\title{
Recent advance in patient monitoring
}

\author{
Tomoki Nishiyama \\ Department of Anesthesiology and Critical Care, Higashi Omiya General Hospital, Saitama, Japan
}

Recent advance in technology has developed a lot of new aspects of clinical monitoring. We can monitor sedation levels during anesthesia using various electroencephalographic (EEG) indices, while it is still not useful for anesthesia depth monitoring. Some attempts are made to monitor the changes in sympathetic nerve activity as one of the indicators of stress, pain/analgesia, or anesthesia. To know the balance of sympathetic and parasympathetic activity, heart rate or blood pressure variability is investigated. For trend of cardiac output, low invasive monitors have been investigated. Improvement of ultrasound enables us to see cardiac structure and function continuously and clearer, increases success rate and decreases complication of central venous puncture and various kinds of nerve blocks. Without inserting an arterial catheter, trends of arterial oxygen tension or carbon dioxide tension can be monitored. Indirect visualization of the airway decreases difficult intubation and makes it easier to teach tracheal intubation. The changes in blood volume can be speculated non-invasively. Cerebral perfusion and metabolism are not ordinary monitored yet, but some studies show their usefulness in management of critically ill. This review introduces recent advances in various monitors used in anesthesia and critical care including some studies of the author, especially focused on EEG and cardiac output. However, the most important is that these new monitors are not almighty but should be used adequately in a limited situation where their meaning is confirmed. (Korean J Anesthesiol 2010; 59: 144-159)

Key Words: Cardiac output, Electroencephalogram, Heart rate variability, Percut aneous carbon dioxide tension, Pulse oximeter, Ultrasound.

Anesthesiologists had used only blood pressure, heart rate, respiratory rate, body temperature, urine volume, and body movement to monitor patients during anesthesia. However, recently, percutaneous oxygen saturation, and end-tidal concentrations of oxygen, carbon dioxide, and inhalation anesthetics have been routine monitors. The most prominent development is seen in the monitor of hypnosis or depth of anesthesia using electroencephalogram (EEG) and then lowor non-invasive cardiac output measurement. Some recent information of these new monitors including the author's experience are shown in this article, especially focused on EEG and cardiac output.

Received: July 19, 2010. Revised: July 23, 2010. Accepted: July 23, 2010.

Corresponding author: Tomoki Nishiyama, M.D., Ph.D., Department of Anesthesiology and Critical Care, Higashi Omiya General Hospital, 4-73-2015, Minami-senju, Arakawa-ku, 116-0003, Japan. Tel: 81-3-3806-7598, Fax: 81-3-3806-7598, E-mail: nishit-tky@umin.ac.jp

(C) This is an open-access article distributed under the terms of the Creative Commons Attribution Non-Commercial License (http:// creativecommons.org/licenses/by-nc/3.0/), which permits unrestricted non-commercial use, distribution, and reproduction in any medium, provided the original work is properly cited. 


\section{EEG}

Monitoring of hypnosis has been enthusiastically investigated using EEG and this is the most prominent progress in clinical monitoring. Spectral edge frequency (SEF)95 or SEF90 is one of the first developed indicators of hypnosis using EEG shown by a simple number. SEF is calculated from the area under the power of frequency obtained by Fourier transformation. The frequency at $95 \%$ from the lower frequency is SEF95. This is quite simple calculation, not complicated as other indices developed later.

The most popular EEG monitor used during anesthesia is the bispectral index (BIS, Aspect Medical, Newton, MA, USA). The BIS is a number from 0 to 100,0 means an isoelectric EEG and 100 means complete awake. While the exact algorithm of BIS has not yet been published, the BIS integrates 4 EEG parameters, relative beta ratio, SynchFastSlow, QUAZI, and burst suppression ratio into a single variable. At a BIS range of 30 to 80 , changes in BIS correlate well with SynchFastSlow. A burst suppression ratio of more than 40 was linearly correlated with BIS in the range of 30 to 0 .

Although BIS is developed to show hypnotic levels during anesthesia, the effects of anesthetics on the EEG differ among various anesthetic drugs. Ganma amino-butyric acid (GABA) receptor agonist induces high amplitude and slow wave in EEG, but N-methyl-D-aspartate (NMDA) receptor antagonist usually shows various patterns in EEG [1]. Fentanyl does not have any effects on EEG with the doses usually used, while high dose fentanyl induces slow wave in the EEG [2]. Remifentanil 0.5 $\mu \mathrm{g} / \mathrm{kg} / \mathrm{min}$ decreased EEG frequency and BIS [3]. Messner et al. reported that the BIS decreased to 33,57 , and 64 by muscle relaxant only [4]. Therefore, even at the same BIS level, hypnotic level might be different depending on the anesthetics used.

Noxious stimulation can change the EEG to fast wave, and the BIS value will then increase, while BIS does not change at insertion of laryngeal mask airway and surgical incision during general anesthesia in our study [5]. In addition, strong noxious stimulation sometimes induces a large delta wave and induces a very low BIS value. This phenomenon is called paradoxical arousal. Therefore, BIS cannot indicate the response to stimuli.

Severe hypercapnia was shown to be accompanied by a decrease in the BIS. During cardiopulmonary bypass, BIS decreased significantly following cooling [6], a decrease of 1.1 BIS per $1^{\circ} \mathrm{C}$ has been reported during temperature changes in hypothermic cardiopulmonary bypass [7]. Whether this shows hypnotic effect of cooling or dissociation between hypnosis and EEG changes is not known.

Two BIS electrodes that were placed in the same patient simultaneously did not always show the same number [8], thus emphasizing the potential influence of electrode placement on intra-individual variability.
Recently many other indices and their devices have been developed.

Entropy (GE Healthcare, Helsinki, Finland) calculates two parameters, State entropy (SE, range 0-91) and Response entropy (RE, range $0-100$ ). SE uses the frequency range $0.8-$ $32 \mathrm{~Hz}$, representing predominantly the EEG activity, RE is calculated at $0.8-47 \mathrm{~Hz}$, consisting of both EEG and facial electromyogram (EMG). The difference of RE-SE can indicate EMG, reflecting nociceptive response [9]. Increased RE is followed by increased SE at nociceptive stimuli in patients not receiving muscle relaxants. Due to their overlapping power spectra, the contribution of EMG and EEG cannot be accurately separated [10]. RE and SE are considered to be interchangeable with BIS during general anesthesia, but during cardiopulmonary bypass in hypothermia, the decrease of SE and RE was more significant than the BIS [6], therefore, in hypothermia, RE and SE are not interchangeable with BIS.

The cerebral state index (CSI) is measured by the Cerebral State Monitor (CSM, Danmeter, Odense, Denmark), a small handy-held apparatus. The CSI is also shown as a number from 0 to 100 and adequate range for general anesthesia is 40 to 60 as the BIS. During sevoflurane-nitrous oxide anesthesia, BIS and CSI showed good agreement by the Bland-Altman plot and correlated well [11]. The CSI tended to stabilize in values of 4060 at intermediate levels of hypnosis, whereas BIS stabilized in values of 20-40 at deeper anesthetic levels [12]. In addition, the CSI better responds to stimuli than the BIS, and recovers faster than the BIS from the noise of electric cautery [11]. Therefore, as a monitor during general anesthesia the CSI might be better than the BIS.

The first version of Narcotrend (Schiller AG, Baar, Switzerland) was complicated. Its algorithm classifies the EEG traces into different stages from A (awake) to F (general anesthesia with increasing burst suppression) [13]. The newest Narcotrend software version includes a dimensionless Narcotrend index from 100 (awake) to 0 (electrical silence). Patient State Index (PSI, Hospirqa, IL, USA) uses neurometrics, which takes into account differences in individual background EEG as well as individual variability of the brain's response to anesthetic agents [14], thereby reducing variance within each individual patient. Index of consciousness (IoC, Morpheus Medical, Barcelona, Spain) is based on the symbolic dynamics. The symbolic dynamics detect the complexity of the EEG that makes it correlate to the depth of anesthesia. The IoC also integrates the beta ratio in light anesthesia and EEG suppression ratio in deep anesthesia [15]. Revuelta et al. [15] showed that during induction of anesthesia, the IoC, BIS and CSI showed the equal $\mathrm{Pk}$ values, while in maintenance of anesthesia, the IoC and BIS showed good agreement with clinical signs, but the CSI was significantly influenced by muscle relaxant. In our experience, 
the BIS and CSI are not influenced by muscle relaxant when anesthesia is deep enough to prevent movement of the patient. The middle-latency auditory evoked potential (MLAEP), extracted from the EEG 10-100 ms after an auditory signal, represents the earliest cortical response to the acoustic stimulus. Amplitudes and latencies of the MLAEP are influenced by anesthetics and surgical stimuli and are therefore believed to be useful for measuring depth of anesthesia $[16,17]$. This is the only one EEG index developed to show the depth of anesthesia using the evoked potentials. There are two different methods to show the EEG response to auditory stimulation, the A-line AEP index (AAI) extracted by advanced signal processing using an average of 15 sweeps measured by the A-line AEP (Danmeter, Odense, Denmark), and the AEP index extracted by a moving time average of 256 sweeps measured by the aepEX (Audiomex, Glasgow, Scotland). Therefore, the AAI changed faster than the AEP index by the aepEX [18]. The AAI might be better to detect response to painful stimuli than the AEP index by the aepEX. The AEP index by the aepEX was larger than the AAI at the same anesthesia level, while both manufacturers suggest the same range of the number for adequate anesthesia [19].

The AAI might be a more sensitive indicator of anesthetic depth (i.e. response to stimuli) than the BIS because the AAI increased at insertion of laryngeal mask airway and surgical incision [5]. BIS, SEF, and AAI could not differentiate anesthesia level between isoflurane $0.5 \%$ and $1.5 \%$ in nitrous oxide anesthesia, and only AAI could detect emergence from anesthesia [20]. The AAI but not the BIS could discriminate slight changes of consciousness during light sedation with propofol infusion in spinal anesthesia [21]. These differences might partly come from the fact that the AAI had smaller variation than the BIS. In addition, the AAI recovered faster from the disturbance by electric cautery than the BIS [22].

When the ranges for adequate hypnosis in general anesthesia recommended by the manufacturers are used, the AAI showed more appropriate numbers, and larger response to stimuli than the BIS and SEF [23]. Thus the AAI might be more reliable monitor of hypnosis in general anesthesia.

The effects of induction doses of intravenous anesthetics on the AAI were studied. The AAI decreased to less than 30 with thiopental and propofol in one minutes, but it increased again in 3 minutes with only thiopental. This means that induction dose of thiopental has significantly shorter duration of hypnosis than propofol. Midazolam decreased AAI slowly to the levels around 30 in 5 minutes, but ketamine increased AAI, although all patients were sedated similarly [24]. Therefore, as same as the BIS, interpretation of the AAI as an indicator of hypnosis depends on the drugs used.

One of the problems of the AAI is that in deep anesthesia as the AAI less than 30, the AEP wave becomes almost flat. To resolve this problem, a composite A-line autoregressive index (composite AAI) is developed. The A-line AEP/2 (Danmeter) monitor calculates composite AAI. This uses the MLAEP for measuring the lighter depths of anesthesia while using spontaneous cortical EEG to measure the deeper levels. During induction of anesthesia, BIS is reported to perform better than composite AAI, while composite AAI is statistically a better discriminator for the level of consciousness during the wake-up test and emergence [25]. The author compared the composite AAI and original AAI. When propofol doses or sevoflurane concentration were the same, composite AAI was larger than the original AAI, while the range for adequate hypnosis recommended by a manufacturer is the same for both indices (Ex. Composite AAI was 60 when original AAI was 40.). When anesthetic level is adequate, original AAI might be better than composite AAI, while we have no comparative experience in deeper anesthesia levels.

Many comparative studies put AEP monitor and other EEG monitor together on the same patients and simultaneously monitored. However, the click sounds of the AEP monitor transiently increased simultaneously measured BIS, SE and RE during sedation with propofol [26], therefore, for study purpose, they should be careful to monitor the EEG and AEP simultaneously in the same patients.

In summary, there are many indices to monitor hypnotic levels during anesthesia, but every time we need to check raw EEG waves besides the index because of some discrepancies between the EEG wave and index and because of the effects of EMG on the index. The EEG effects of anesthetic drugs are not good predictors of movement in response to a surgical stimulus because the main site of action for anesthetic drugs to prevent movement is the spinal cord [27]. The use of these monitors in children is not as well understood as in adults. [27].

\section{Skin Conductance}

As shown in the previous section, EEG changes cannot indicate level of analgesia. Increased activity in cortical and subcortical regions of the brain as a result of arousal or noxious stimuli leads to a higher rate of firing in sympathetic, postganglionic cholinergic neurons [28-30]. This results in filling of sweat glands, which is measured by skin conductance [31]. Skin conductance is measured by the MEDSTORM AS 2005 (Medstorm Innovations, Oslo, Norway). The number of fluctuations within the mean skin conductance (NFSC) was reported to perform similarly to BIS during sevofluraneremifentanil anesthesia [34]. This suggests that the NFSC is an indicator of hypnosis not analgesia. However, NFSC showed a significant correlation with level of noxious stimuli during anesthesia [32]. In addition, the severity of postoperative 
pain significantly influences skin conductance. NFSC was significantly different between patients with different numeric rating scale of pain [33]. The derivative of the mean skin conductance level, another index of skin conductance showed a similar discrimination with RE and SE in entropy between sound responses at the different sedation levels [35]. However, NFSC was better than RE-SE for the measurement of clinical stress during intubation, and was sensitive to tetanic stimuli at different opioid analgesic levels as contrast with RE-SE [36]. Therefore, NFSC might be able to detect pain, while further studies are necessary to confirm it.

The similar parameter is a skin impedance measured by an electrosympathicograph (ESG 1001 Monitor-System, Dr. Janitzki Consulting Engineers, Altenbeken, Germany). The changes in the impedance correlated well with the changes in the BIS during target control infusion of propofol [37]. Only one study is found to investigate a skin impedance, therefore, whether this is used as a monitor of analgesia (anesthesia) or hypnosis is not known.

In summary, skin conductance or impedance has been investigated for many years, but only recently it can be studied in clinical practice. However, still it is complicated for setting up to use as a routine monitor and only a few data are available. Further improvement and studies are necessary.

\section{Other Indices Targeting for Depth of Anesthesia}

Surgical stress index (SSI) is based on the normalized pulse beat interval and photoplethysmographic pulse wave amplitude and it is developed to assess surgical stress and analgesia. In the study for postoperative pain, the difference between different pain score might be larger in the SSI than that in the skin conductance [38]. When SSI was used to control remifentanil administration, it decreased remifentanil consumption, and gave more stable hemodynamics and lower incidence of unwanted events than without SSI [39].

The noxious stimulation response index (NSRI) is calculated from the weighted propofol and remifentanil concentrations corrected for interaction and normalized to a range between 0 and 100 , where 100 reflects $100 \%$ probability and values approaching 0 reflect close to $0 \%$ probability of responding to laryngoscopy. The NSRI better predicted the response to noxious stimulation of the forearm than the BIS, although the BIS better predicted measure of hypnosis [40]. However, this is available only for propofol-remifentanil anesthesia.

The RIII reflex as a component of the nociceptive flexion reflex is a polysynaptic spinal withdrawal reflex that is elicited by stimulation of nociceptive nerve afferents. The RIII reflex threshold correlates with non-responsiveness better than the
BIS in propofol-remifentanil anesthesia [41]. To assess the RIII reflex, biceps femoris muscle activity is monitored using an electromyogram during the application of electrocutaneous stimuli to the ipsilateral sural nerve. The procedure of setting up to record the reflex is much more complex than simply applying EEG and takes more time. This is a disadvantage of the RIII reflex as a monitor. In addition, normalization of the RIII reflex threshold is necessary for inter-individual compatibility. Therefore, RIII reflex cannot be applied when anesthesia has already been started.

In summary, these new concepts are more complicated than EEG and skin conductance. We need much more studies to apply these new monitors to show anesthesia depth in clinical practice.

\section{Heart Rate or Blood Pressure Variability}

To know stress response during anesthesia, plasma catecholamine concentrations have been measured. However, this is not continuous monitoring and we cannot get the results on time. Beat-to-beat variations in heart rate largely reflects fluctuations in sympathetic and parasympathetic activity at the sino-atrial node. Several linear and non-linear methods have been used to assess heart rate variability (HRV). The most frequently used linear method is the power spectral analysis of R-R interval defining low frequency component (LF) and high frequency component (HF) [42]. LF $(0.04-0.15 \mathrm{~Hz})$ reflects cardiac sympathetic and parasympathetic nerve activity, HF $(0.15-0.4 \mathrm{~Hz})$ represents cardiac parasympathetic nerve activity, and LF/HF ratio represents the balance between sympathetic and parasympathetic activities. The HF is significantly dependent on the respiratory rate and not on the tidal volume [43]. If the respiratory rate is less than 8 breaths per minute, it is difficult to separate the high-frequency peak in the power spectrum from the low-frequency peak. In addition, changes in carbon dioxide affect HRV. High carbon dioxide concentration increases HF and LF, but this reactivity is abolished during general anesthesia [44]. Another linear method calculates standard deviation of R-R interval and root of mean squared difference between successive R-R interval (RMSSD). Nonlinear method such as spectral entropy is better suited for non-stationary signals as may occur in patients under noxious stimulation [45]. Entropy quantifies the repetition of patterns in the signal. Larger values of entropy correspond to greater apparent randomness or irregularity, whearas smaller values correspond to more instances of recognizable patterns in the data [46]. The entropy is reported to reflect parasympathetic modulation of heart rate under varying physiologic conditions and in response to pharmacological denervation [47]. Entropy increased by laryngeal mask airway insertion, while LF and 
LF/HF increased by surgical stimuli [48]. Thus, the response to different stimuli might be different between entropy and LF, LF/ $\mathrm{HF}$.

For analysis of HRV, recordings of 5 minutes should be made under physiologically stable conditions processed by the frequency domain method [49]. Spectral analysis of HRV is not appropriate for the assessment of autonomic nervous activities when heart rate is unstable or changing progressively. Although the time course of total power and LF/HF seems to follow the BIS and the plasma levels of stress hormones, there were only weak correlations between the LF/HF ratio and the level of norepinephrine [50].

The variability of blood pressure is also investigated. The LF of blood pressure variability (LFBP) is considered to be indicative of peripheral vasomotor sympathetic activity and modulation [51]. The HF of blood pressure variability (HFBP) is reported to be mediated largely by the mechanical effect of respiration on intrathoracic pressure and/or cardiac filling [51,52].

There are many studies of HRV in anesthesia, but some discrepancies exist among the studies. Barbiturate decreased both LF and HF $[53,54]$. Thiopental and fentanyl could not inhibit the increases in HF and LF/HF at tracheal intubation [55]. Propofol decreased HF and entropy without significant changes in LF, suggesting sympathetic dominance [53], while Win et al. [56] reported that total power, LF, HF, LF/HF, and entropy were significantly decreased in propofol sedated patients compared with awake patients. Kanaya et al. showed no change in LF/HF by induction with propofol [57]. Etomidate showed no effects on LF and HF [53], while Zickmann et al. [54] reported that etomidate decreased both LF and HF. Midazolam was reported to decrease HF and LF but did not change LF/HF [56]. However, Komatsu et al. showed that midazolam increased HF and decreased LF [58]. Midazolam and fentanyl decreased LF [54], did not change HF and LF/HF and inhibited these increases by tracheal intubation [55]. From these different results in different studies, it is suggested that HRV is quite variable depending on the situation tested, which means it is not useful to measure sympathetic and parasympathetic activity in anesthesia.

In sevoflurane anesthesia, LF decreased with a reduction in the BIS. Entropy and HF decreased after induction of anesthesia, but no further decrease was observed in spite of a reduction in the BIS [57]. Sevoflurane-nitrous oxide decreased HF and inhibited the increase in $\mathrm{HF}$ and LF/HF by tracheal intubation [55]. In sevoflurane-nitrous oxide anesthesia, LFBP, LF and HF decreased significantly. In propofol-fentanyl anesthesia, LFBP and LF decreased significantly. The degree of reduction in LFBP was greater in sevoflurane-nitrous oxide anesthesia than in propofol-fentanyl anesthesia [59]. These results suggest that reduction in autonomic nervous modulation to the heart might not be different between sevoflurane-nitrous oxide anesthesia and propofol-fentanyl anesthesia, while reduction in sympathetic nervous modulation to peripheral vasculature is greater in sevoflurane-nitrous oxide anesthesia than in propofol-fentanyl anesthesia. During light anesthesia, LF was more suppressed by sevoflurane than by propofol, and propofol markedly increased LF/HF [60].

In spinal anesthesia, some patients with a low block level developed a marked increase in LF/HF, which was abolished by supplementation with intrathecal fentanyl, but not intravenous fentanyl [61]. Activation of the sympathetic nervous system in the upper body may be elicited as a compensatory mechanism for vasodilation in the lower body caused by spinal anesthesia when anesthesia level is low.

In summary, considering of these various results and author's experience that the absolute value of HRV parameter has large variations, further improvement is necessary to use HRV as an ordinal monitor of cardiac sympathetic and parasympathetic activities, and blood pressure variability may be the same.

\section{Low-or Non-invasive Cardiac Output Monitoring}

Cardiac output has been measured intermittently by transpulmonary thermodilution methods using a Swan-Ganz catheter. Vigilance $^{\mathrm{TM}}$ (Edwards LifeSciences, Irvine, CA, USA) enables continuous monitoring of cardiac output using a Swan-Ganz catheter, while we well know that continuous measurements do not agree with intermittent bolus thermodilution measurements.

Recently, many kinds of low-or non-invasive cardiac output monitoring have been developed without a pulmonary thermodilution catheter. Pulse contour analysis is the most ordinal method to measure cardiac output in less invasive monitoring.

FloTrac $^{\mathrm{TM}}$ and Vigileo ${ }^{\mathrm{TM}}$ system (Edwards LifeSciences, Irvine, CA, USA) uses arterial pulse waveform analysis of radial artery to measure cardiac output. FloTrac ${ }^{\mathrm{TM}}$ and Vigileo ${ }^{\mathrm{TM}}$ system do not need manual calibration. It calibrates itself on the basis of patient's characteristic data in conjunction with internal correction variables.

Cardiac output measured by FloTrac ${ }^{\mathrm{TM}}$ and Vigileo ${ }^{\mathrm{TM}}$ correlated well with cardiac output measured by transpulmonary thermodilution for patients being paced or in sinus rhythm and poor for patients in atrial fibrillation [62]. Lorsomradee et al. reported that cardiac output measured by FloTrac ${ }^{\mathrm{TM}}$ and Vigileo $^{\mathrm{TM}}$ and that by Vigilance ${ }^{\mathrm{TM}}$ yield comparable results during cardiac surgery with cardiopulmonary bypass [63] However, phenylephrine administration decreased cardiac output by Vigilance ${ }^{\mathrm{TM}}$ and increased that by FloTrac ${ }^{\mathrm{TM}}$ and Vigileo $^{\mathrm{TM}}$ [63]. The repeatability of cardiac output measured by transpulmonary thermodilution, as well as of cardiac output 
measured by FloTrac ${ }^{\mathrm{TM}}$ and Vigileo ${ }^{\mathrm{TM}}$ is reduced in patients with aortic stenosis. The repeatability of both methods, as well as the agreement between methods, decreased significantly immediately after termination of cardiopulmonary bypass [64] In mechanically ventilated patients with circulatory failure after liver transplantation, stroke volume variation by FloTrac ${ }^{\mathrm{TM}}$ and Vigileo $^{\mathrm{TM}}$ is a useful predictor of increased cardiac output in response to volume expansion and cardiac output measured by FloTrac ${ }^{\mathrm{TM}}$ and Vigileo ${ }^{\mathrm{TM}}$ is able to track changes in cardiac output induced by volume expansion [65]. In contrast, Matthieu et al. reported that cardiac output obtained with FloTrac ${ }^{\mathrm{TM}}$ and Vigileo ${ }^{\mathrm{TM}}$ in patients undergoing liver transplantation do not agree with thermodilution measurements, particularly in patients with low systemic vascular resistance as attested by Child-Pugh grade B and C [66]. Stroke volume variation obtained by FloTrac ${ }^{\mathrm{TM}}$ and Vigileo ${ }^{\mathrm{TM}}$ predicts fluid responsiveness with an acceptable sensitivity and specificity and is also a potential surrogate for continuous monitoring of the respiratory variation in arterial pulse pressure in mechanically ventilated patients [67]. However, interpretation of stroke volume variation should be cautious in patients with spontaneous breathing, arrhythmia, open chest condition, and ventricular dysfunction. Stroke volume variation obtained by FloTrac $^{\mathrm{TM}}$ and Vigileo ${ }^{\mathrm{TM}}$ is reported not to be a reliable predictor of fluid responsiveness in major abdominal surgery [68]. Prone position induced a significant increase in pulse pressure variation and stroke volume variation measured by FloTrac ${ }^{\mathrm{TM}}$ and Vigileo ${ }^{\mathrm{TM}}$, but did not alter their abilities to predict fluid responsiveness [69].

PulseCO $^{\mathrm{TM}}$ (LiDCO, London, UK) relies on a pulse power analysis, which is based on the principle of mass/power conservation in a system and the assumption that following the correction for compliance and calibration. PulseCO ${ }^{\mathrm{TM}}$ provides stroke volume from the arterial pressure waveform of radial artery using an autocorrelation algorithm. The algorithm calculates nominal stroke volume after a pressure to volume transformation and it is converted to actual stroke volume by calibration using lithium dilution measurement $\left(\mathrm{LiDCO}^{\mathrm{TM}}\right.$ system). Lithium is rapidly redistributed and has no first pass loss from the circulation. Lithium calibration cannot be used in patients who have recently (in 15 to $30 \mathrm{~min}$ ) received neuromuscular blockers because these drugs react with the lithium sensor.

Cardiac output measured by PulseCO ${ }^{\mathrm{TM}}$ calibrated with thermodilution performs well as a continuous cardiac output monitor and shows acceptable agreement with pulmonary thermodilution in off-pump coronary artery bypass surgery [70]. However, our study showed that cardiac output measured by PulseCO ${ }^{\mathrm{TM}}$ was not interchangeable with that measured by Vigilance $^{\mathrm{TM}}$ even when PulseCO ${ }^{\mathrm{TM}}$ is calibrated with the data of
Vigilance $^{\mathrm{TM}}$ at first in off-pump coronary artery bypass surgery [71]. Agreement between intermittent and continuous cardiac output values obtained with the $\mathrm{LiDCO}^{\mathrm{TM}}$ and Vigilance ${ }^{\mathrm{TM}}$ was found to be clinically acceptable in patients with hyperdynamic circulation [72], while PulseCO ${ }^{\mathrm{TM}}$ might underestimate cardiac output compared to that by bolus transpulmonary thermodilution when simply decreasing systemic vascular resistance by infusion of prostaglandin E1 in cardiac surgery [73]. Pulse pressure variation and systolic volume variation measured by $\mathrm{LiDCO}^{\mathrm{TM}}$ can predict fluid responsiveness in mechanically ventilated patients during general anesthesia [74].

PiCCO $^{\mathrm{TM}}$ (Pulsion, Munich, Germany) uses a thermistertipped catheter usually introduced into the femoral artery that is used to track stroke volume on a beat-by-beat basis after calibration by transpulmonary thermodilution. The measurement with a radial artery catheter (50 cm, Pulsion) is interchangeable with that derived from a pulmonary catheter in patients with coronary artery bypass surgery, and that a centrally inserted arterial catheter is required for accurate determination of cardiac output by $\mathrm{PiCCO}^{\mathrm{TM}}$ [64]. Cardiac output measured by $\mathrm{PiCCO}^{\mathrm{TM}}$ is most often found to be higher than the corresponding cardiac output measured by transpulmonary thermodilution, and this is considered to be caused by the cold-induced reduction in heart rate [76] and the loss of indicator [77]. Continuous cardiac output determination using $\mathrm{PiCCO}^{\mathrm{TM}}$ is a reliable method of assessing cardiac output up to 5 hour without recalibration in porcine septic shock model [78]. When systemic vascular resistance decreased by prostaglandin $\mathrm{E} 1, \mathrm{PiCCO}^{\mathrm{TM}}$ underestimate cardiac output up to $40 \%$ compared with that by thermodilution method [79].

Intrathoracic blood volume calculated by $\mathrm{PiCCO}^{\mathrm{TM}}$ shows cardiac preload [80] and extravascular lung water is an indicator of acute pulmonary edema [81]. Stroke volume variation calculated by $\mathrm{PiCCO}^{\mathrm{TM}}$ is affected by the depth of tidal volume under mechanical ventilation [82]. However, the presence of severe arrhythmias, valvular regurgitation, or intra- or extra cardiac shunts gives inaccurate results [78]. The pulse pressure variation and stroke volume variation are only reliable in fully sedated, mechanically ventilated patients with a relatively high tidal volume.

Non-invasive cardiac output measurement is performed with the HDI/Pulse Wave CR-2000 Cardiovascular Profiling Instrument $^{\mathrm{TM}}$ (Hypertension Diagnostics, Inc., Eagan, MN, USA). With this, radial artery pressure waveforms are obtained non-invasively using a tonometer applied to the skin of the distal forearm overlying the radial artery. The arterial pressure waveforms are calibrated with a blood pressure cuff. In critically ill hemodynamically unstable patients, cardiac output measured by the HDI/Pulse Wave CR-2000 Cardiovascular Profiling Instrument ${ }^{\mathrm{TM}}$ was significantly lower than those 
measured by tarns pulmonary thermodilution or $\mathrm{PiCCO}^{\mathrm{TM}}$ [83]. A significant increase in the invasively determined cardiac output (by thermodilution or $\mathrm{PiCCO}^{\mathrm{TM}}$ ) was observed when a fluid bolus was administered, though these changes were not reflected by the non-invasive method by the HDI/Pulse Wave CR-2000 Cardiovascular Profiling Instrument ${ }^{\mathrm{TM}}$ [83].

Wesseling's cZ method (BMEYE, Academic Medical Center, Amsterdam, the Netherlands) relates cardiac output to the area under the systolic portion of the arterial pressure wave. Dividing area under the systolic portion of the arterial pressure wave by aortic impedance provides a measure of stroke volume. The Modelflow method (BMEYE) simulates the classical three-element Windkessel model; characteristic impedance, Windkessel compliance, and peripheral resistance to estimate cardiac output. The Hemac pulse contour method is based on a three-element Windkessel model similar to the Modelflow method. The Modelflow method uses in vitro non-linear relations between cross-sectional are of the aorta and arterial pressure described by Langewouters [84], while the Hemac method uses in vivo measurements of patients to correct the Langewouters relations. Among the $\mathrm{PiCCO}^{\mathrm{TM}}, \mathrm{LiDCO}^{\mathrm{TM}}$, Modelflow method, Wesseling's cZ method, and Hemac method, Modelflow and Hemac methods showed the best results in absolute values and in tracking changes in cardiac output in patients without congestive heart failure, with normal heart rhythm and reasonable peripheral circulation [85].

The partial $\mathrm{CO}_{2}$ rebreathing method $\left(\mathrm{NICO}^{\mathrm{TM}}\right.$, Novametrix Medical Systems, Wallingford, CT, USA) uses changes in $\mathrm{CO}_{2}$ elimination and end-tidal $\mathrm{CO}_{2}$ measured in response to a brief rebreathing period to calculate pulmonary blood flow. NICO $^{\mathrm{TM}}$ provides an accurate estimate of cardiac output after induction of anesthesia, but underestimates cardiac output after aortic cross clamping and declamping in abdominal aortic aneurysm surgery [86]. Continuous cardiac output measured by Vigilance ${ }^{\mathrm{TM}}$ shows a relatively smaller degree of bias than $\mathrm{NICO}^{\mathrm{TM}}$ but overestimates cardiac output at the end of the surgery [86]. In the author's experience, $\mathrm{NICO}^{\mathrm{TM}}$ is quite unstable to have large variations in a stable hemodynamic state during general anesthesia.

Thoracic electrical bioimpedance is based on the theory that the thorax is a cylinder that is perfused with a fluid (blood) of a specific resistivity. Thoracic bioimpedance is the electrical resistance to high frequency low amplitude current that is transmitted from electrodes placed on the upper and lower thorax. Thoracic bioimpedance is affected by tissue fluid volume and changes in the volume of pulmonary and venous blood induced by respiration. Intraoperative environment is not conductive to thoracic electrical bioimpedance measurements of cardiac output due to interference by noise from electric cautery, mechanical ventilation and surgical manipulation. Thoracic electrical impedance method (BioZ. $\operatorname{com}^{\mathrm{TM}}$; Cardiodynamics International, Now SonoSite, Seattle, WA, USA) does not correlate with continuous measurement by Vigilance ${ }^{\mathrm{TM}}$ in cardiac surgery [87]. Cardiac output measurements by thoracic electrical bioimpedance/electrical velocimetry (Aesculon, Osypka Medical, Berlin, Germany) and that measured by $\mathrm{PiCCO}^{\mathrm{TM}}$ were not interchangeable in septic patients [88].

Flow measurement by pulse-wave Doppler across a cardiac valve or in the left ventricular outflow tract and the assessment of the cross-sectional area at the site of the flow quantification (aortic valve) allow cardiac output measurement by transesophageal echocardiography. A Doppler beam orientation strictly parallel to the blood flow and an unchanged cross-sectional area over time are needed for optimal measurement. Esophageal Doppler only measures descending aortic blood flow, and excludes flow to the aortic arch vessels. This method is highly operator dependent. Both esophageal Doppler and pulse contour analysis by PiCCO $^{\mathrm{TM}}$ lack sufficient accuracy to measure rapidly changing beat-to-beat stroke volume over a short time period under a wide range of conditions [89]. The real benefit of echocardiography is the visualization of ventricular function, wall motion abnormalities and cardiac filling as well as the real time guidance of fluid therapy in acute, critical hemodynamic situations.

In summary, many low- or non-invasive measurements of cardiac output have been developed, but all of these can be used to observe the changes of cardiac output only in almost normal heart, not in low or high cardiac output, valvular diseases, or arrhythmias.

\section{Ultrasound}

As shown in the previous section, transesophageal echocardiography is useful for the visualization of ventricular function, wall motion abnormalities, embolic and thrombotic structures, and cardiac filling as well as the real time guidance of fluid therapy in acute, critical hemodynamic situations. Practice guidelines for perioperative transesophageal echocardiography is published in Anesthesiology [90]. For adult patients in open heart surgery, transesophageal echocardiography should be used to confirm preoperative diagnosis, detect unsuspected pathology, adjust intraoperative management, and assess the results of surgery. In non-cardiac surgery, for patients with suspected hemodynamic, pulmonary, or neurologic compromise, transesophageal echocardiography may be useful. However, this is one of the invasive monitors to have potential complications such as esophageal perforation, esophageal injury, hematoma, laryngeal palsy, dysphagia, and dental injury. Therefore, this should be used only for the patients who 
really can get benefit from echocardiography.

Ultrasound is also quite useful for vascular access such as central venous cannulation [91] and arterial cannulation [92] decreasing neurological complications and pneumothorax. It is well known that ultrasound-guided cannulation of internal jugular vein decreases arterial puncture and multiple attempts, and decreases the time for cannulation [91]. In contrast to the internal jugular vein, ultrasound guided access to the subclavian or axillary vein is sometimes difficult in central part of subclavian vein due to the sound barrier generated by the clavicle bone, while lateral approach can visualize the vein [93].

Recent most prominent advance in ultrasound is its use in peripheral nerve block. Using the ultrasound to depict the nerve and surround structures can make the needle direction to reduce unintended violation of vessels and organs [94]. To improve the discrimination of the needle, some modifications of needles are performed $[95,96]$. Thus, ultrasound guidance shortens the block performance time and reduces the number of needle passes [97]. The visually controlled injection of the local anesthetic ideally results in a circumferential spread around the targeted nerve [98], reduction of the volume of local anesthetic [99], and decrease in the onset time of the block [100]. For a catheter insertion in peripheral nerve, ultrasound guide is also useful to improve effectiveness and decreases the number of needling and procedural pain [101]. Epidural puncture is sometimes difficult by blind loss of resistance method, especially in obese patients. The potential of ultrasound-guided epidural puncture is somewhat limited by the interfering bone structure and the relatively deep position of the epidural space, which detracts from the quality of the images [102]. In children, usually regional anesthesia is performed under general anesthesia. Therefore, ultrasound-guided block is useful to decrease complications [103].

Most recent advances are using three- or four-dimensional ultrasound imaging $[104,105]$ and changing the ultrasound beam insertion angle to detect the insertion needle better. However, most important in using ultrasound is to learn anatomy specified for ultrasound.

In summary, now ultrasound is quite useful to monitor cardiac performance, to insert some kinds of catheters, to perform various kinds of nerve block. We need to learn anatomy for ultrasound.

\section{Percutaneous Oxygen and Carbon Dioxide Tension}

Percutaneous oxygen saturation $\left(\mathrm{SaO}_{2}\right)$ measured by pulse oximetry is now a routine monitor of oxygenation. However, $\mathrm{SaO}_{2}$ shows oxygen binding to hemoglobin, not dissolved oxygen measured as an arterial oxygen tension $\left(\mathrm{PaO}_{2}\right)$. The arterial carbon dioxide tension $\left(\mathrm{PaCO}_{2}\right)$ is an important indicator of respiratory function and ventilation during anesthesia, sedation, and in the intensive care unit. To measure $\mathrm{PaO}_{2}$ and/or $\mathrm{PaCO}_{2}$, arterial puncture or cannulation and withdrawal of blood are necessary. End-tidal carbon dioxide tension $\left(\mathrm{EtCO}_{2}\right)$ monitoring is non-invasive and continuous monitoring in intubated patients, but it is not accurate in nonintubated patients and underestimates $\mathrm{PaCO}_{2}[106]$.

Percutaneous measurements of oxygen tension $\left(\mathrm{tcPO}_{2}\right)$ and carbon dioxide tension $\left(\mathrm{tcPCO}_{2}\right)$ are non-invasive and are investigated much in infants [107] because it is difficult to insert arterial catheter and not so much blood can be withdrawn in infants. Several monitors to measure tcPO $\mathrm{PO}_{2}$ and/or tcPCO and/or $\mathrm{tcPO}_{2}$ have been developed. TCM $400^{\mathrm{TM}}$ (Radiometer, Copenhagen, Denmark) can measure $\mathrm{tcPO}_{2}$ simultaneously at 6 locations. $\mathrm{TCM}^{\mathrm{TM}}$ and $\mathrm{TCM} 4^{\mathrm{TM}}$ (Radiometer) can measure tcPO ${ }_{2}$ and $t c \mathrm{PCO}_{2}$ with one electrode. SenTec Digital Monitor ${ }^{\mathrm{TM}}$ (Sentec AG, Therwil, Switzerland) and TOSCA ${ }^{\mathrm{TM}}$ (Linda Medical Sensors, Basel, Switzerland) use ear sensor to measure tcPCO and $\mathrm{SpO}_{2}$. All the monitors use the electrode as same as that used in blood gas analyzer; the Clark type electrode for $\mathrm{tcPO}_{2}$ and glass $\mathrm{pH}$ electrode for $\mathrm{tcPCO}_{2}$ with chloride silver electrode as a reference [108].

The electrodes of the $\mathrm{TCM} 3^{\mathrm{TM}}$ and $\mathrm{TCM} 4^{\mathrm{TM}}$ can be put anywhere. In our study, $\mathrm{tcPO}_{2}$ and $\mathrm{PaO}_{2}, \mathrm{tcPCO}_{2}$ and $\mathrm{PaCO}_{2}$ or $\mathrm{EtCO}_{2}$ correlated well when the electrode of $\mathrm{TCM} 4{ }^{\mathrm{TM}}$ was put on the chest, but not on the upper arm or forearm during general anesthesia for abdominal surgery [109]. However, limits of agreement were too large to use tcPO and $\mathrm{tcPCO}_{2}$ as surrogate measures of $\mathrm{PaO}_{2}$ and $\mathrm{PaCO}_{2}$ wherever the electrode was put on during general anesthesia in adult [109]. In patients after elective cardiac surgery, the best agreement between $\mathrm{tcPCO}_{2}$ measured by TOSCA ${ }^{\mathrm{TM}}$ and $\mathrm{PaCO}_{2}$ was found during normoand hypoventilation [110]. In this study, Baulig et al. [110] suggested that the location of the sensor at the ear lobe might not be the optimal place for transcutaneous detection of oxygen saturation and pulse rate in patients early after cardiac surgery.

To arterialize capillary, skin under the electrode should be heated, but high temperature causes burn injury. The electrode of the TCM $4^{\mathrm{TM}}$ should be heated to at least $43^{\circ} \mathrm{C}$ to have good correlation of $\mathrm{tcPO}_{2}$ and $\mathrm{tcPCO}$ with $\mathrm{PaO}_{2}$ and $\mathrm{PaCO}_{2}$ [111]. Less than 2 hours continuous monitoring induced no burn injury [111]. In the majority of patients, an initial overshoot and/or a drift to lower $\mathrm{tcPCO}_{2}$ was observed with SenTec Digital Monitor $^{\mathrm{TM}}$ [110]. An initial heating of the ear sensor to $45^{\circ} \mathrm{C}$ for the first $15 \mathrm{~min}$. and then a decrease to $42^{\circ} \mathrm{C}$ prevented the overshoot and provided valid tcPCO $\mathrm{PC}_{2}$ [112].

TcPCO ${ }_{2}$ and $\mathrm{EtCO}_{2}$ correlated well with $\mathrm{PaCO}_{2}$ during general anesthesia, while the difference between $\mathrm{EtCO}_{2}$ and $\mathrm{PaCO}_{2}$ was greater than that between $\mathrm{tcPCO}_{2}$ and $\mathrm{PaCO}_{2}[113]$. 
$\mathrm{TcPCO}_{2}$ by $\mathrm{TCM}^{\mathrm{TM}}$ was more accurate than $\mathrm{EtCO}_{2}$ in patients receiving artificial ventilation via an endotracheal tube and it was also more accurate than the nasal $\mathrm{EtCO}_{2}$ in patients breathing spontaneously [114]. $\mathrm{TcPCO}_{2}$ measured by $\mathrm{TOSCA}^{\mathrm{TM}}$ demonstrated better agreement with $\mathrm{PaCO}_{2}$ than nasal $\mathrm{EtCO}_{2}$ for patients under monitored anesthesia care with deep sedation.

$\mathrm{TcPCO}_{2}$ was reported to be more sensitive for detection of hypoventilation than $\mathrm{EtCO}_{2}$ [115]. Kopka et al. [116] and McCormack et al. [117] showed that $\mathrm{tcPCO}_{2}$ was useful to detect hypoventilation by analgesia after surgery. However, they had no any other monitors, as a control to compare with $\mathrm{tcPCO}_{2}$, therefore, its usefulness is questionable. Nasal EtCO is inaccurate because patients breathe through both nose and mouth.

There was insufficient agreement between $\mathrm{tcPCO}_{2}$ derived from SenTec Digital Monitor ${ }^{\mathrm{TM}}$ or TOSCA ${ }^{\mathrm{TM}}$ and $\mathrm{PaCO}_{2}$ for both the absolute values and trends [118]. During general anesthesia, ear and face become cold. Therefore, even if ear sensor is heated, the difference between $\mathrm{tcPCO}_{2}$ and $\mathrm{PaCO}_{2}$ might be larger than that sensor is put on the trunks considered from the author's experience.

It is well recognized that the absolute value of $\mathrm{tcPO}_{2}$ is far from $\mathrm{PaO}_{2}$. However, as shown above, $\mathrm{tcPO}_{2}$ and $\mathrm{PaO}_{2}$ correlated well when the electrode of TCM $4^{\mathrm{TM}}$ was put on the chest [109]. Therefore, only the trend is useful to use $\mathrm{tcPO}_{2}$ as surrogate of $\mathrm{PaO}_{2}$.

In spinal anesthesia, vasodilation occurs in anesthetized area by sympathetic block. The author investigated the changes in $\mathrm{tcPO}_{2}$ in spinal anesthesia whether we can detect sympathetic block by changes in $\mathrm{tcPO}_{2}$. $\mathrm{TcPO}_{2}$ increased in the anesthetized area by spinal anesthesia. After oxygen administration, the increase in $\mathrm{tcPO}_{2}$ was larger in the non-anesthetized area, although the absolute values were not different between anesthetized and non-anesthetized areas [119]. Therefore, measurement of $\mathrm{tcPO}_{2}$ may have a role to check anesthesia level of spinal anesthesia when patient cannot answer to questions and cannot respond to stimuli.

In summary, $\mathrm{tcPCO}_{2}$ can be used to know the changes of $\mathrm{PaCO}_{2}$ when the electrode is put on the trunks at $43^{\circ} \mathrm{C}$, while the availability of $\mathrm{tcPO}_{2}$ is lower than $\mathrm{tcPCO}_{2}$.

\section{Airway Observing Device}

For tracheal intubation, laryngoscopy with Macintosh or Miller blade has been ordinally used. In recent years, advances in optical technologies have facilitated the development of multiple novel indirect laryngoscopes. There are tremendous publications of airway observing devices. To view the larynx during laryngoscopy, a head-mounted camera (Airway Cam ${ }^{\mathrm{TM}}$,
Airway Cam Technologies, Wayne, PA, USA) was first developed for training purpose [120], but the camera interferes with the trainee's line of sight and the view was still limited to the $15^{\circ}$ of a standard Macintosh blade. A superior system has been developed in which both a light source and micro camera are at the tip of the laryngoscope, one using a special laryngoscope (GlideScope $^{\mathrm{TM}}$; Verathon Medical, Bothell, WA, USA) and the other using a standard Macintosh blade (BERCI DCI ${ }^{\mathrm{TM}}$ Video Laryngoscope; Karl Stolz, Tuttlingen, Germany). Both have a display monitor mounted on a standing pole or on the table. In the study of teaching laryngoscopy to trainee, BERCI DCI $^{\mathrm{TM}}$ Video Laryngoscope showed the benefit to decrease number of attempts and repositioning and teeth trauma [121]. GlideScope $^{\mathrm{TM}}$ significantly improved the laryngeal exposure to facilitate tracheal intubation [122].

Some new devices have display monitor on the laryngoscope. The anatomically shaped blades of the Airway Scope ${ }^{\text {TM }}$ (Pentax, Tokyo, Japan) and Airtraq ${ }^{\text {TM }}$ (Prodol Meditec, Vizcaya, Spain) do not require alignment of the oral, pharyngeal, and tracheal axes to visualize the glottic opening, and, therefore, less force is applied during laryngoscopy. The differences between these two are, Airway Scope ${ }^{\mathrm{TM}}$ is designed to use as a Miller blade (with the tip of the blade under the epiglottis), but Airtraq ${ }^{\mathrm{TM}}$ is recommended to use as a Macintosh blade (with the tip of the blade in the vallecula), the Airway Scope ${ }^{\mathrm{TM}}$ has shorter distance from the tip of the blade to camera or lens than Airtraq ${ }^{\mathrm{TM}}$, which gives wider view of the Airtraq ${ }^{\mathrm{TM}}$. In our study by expert anesthesiologists, Macintosh laryngoscope was better than the Airway Scope ${ }^{\mathrm{TM}}$ and the Airtraq ${ }^{\mathrm{TM}}$ in patients with Cormack and Lehane classification 1 or 2, while these two were better than the Macintosh laryngoscope in patients with Cormack and Lehane classification 3 or 4 (personal communication). The time to intubation with Airway Scope ${ }^{\mathrm{TM}}$ was significantly shorter than with Airtraq ${ }^{\mathrm{TM}}$ and Macintosh laryngoscope for medical students in manikin study [123].

Tracheal intubation with Airway Scope ${ }^{\mathrm{TM}}$ but not with the Glidescope $^{\mathrm{TM}}$ decreased hemodynamic changes by intubation compared with the Macintosh laryngoscope [124]. Tan et al. [125] also showed that the Airway Scope ${ }^{\mathrm{TM}}$ is better to improve tracheal intubation than Glidescope ${ }^{\mathrm{TM}}$ in a manikin study. The use of Airway Scope ${ }^{\mathrm{TM}}$ may be impaired in patients with difficult mouth opening, because the width of the blade is greater than Macintosh laryngoscope. From this reason, for morbid obese patients, sometimes Macintosh laryngoscope is better than the Airway Scope ${ }^{\mathrm{TM}}$ in our experience.

Truview EVO2 ${ }^{\mathrm{TM}}$ (Truphatek International, Netanya, Israel) laryngoscope blade incorporates an optic side port to its curved blade and provision for $\mathrm{O}_{2}$ insufflation. In manikin study, in the simulated easy laryngoscopy scenarios, there was no difference among the Airway Scope ${ }^{\mathrm{TM}}$, Truview $\mathrm{EVO}^{\mathrm{TM}}{ }^{\text {, Glidescope }}{ }^{\mathrm{TM}}$ 
and Macintosh laryngoscope [126]. In more difficult tracheal intubation scenarios, Glidescope ${ }^{\mathrm{TM}}$ and Airway Scope ${ }^{\mathrm{TM}}$, and to a lesser extent TruviewEVO2 ${ }^{\mathrm{TM}}$ demonstrated advantages over the Macintosh laryngoscope including a better view of the glottis, greater success of tracheal intubation, and ease of device use [126]. Airway Scope ${ }^{\mathrm{TM}}$ was more successful in achieving tracheal intubation, required less time for intubation, caused less dental trauma.

McGrath $^{\text {TM }}$ (Aircraft Medical, Edinburgh, UK) is a selfcontained video laryngoscope. For the trainees, duration of intubation was longer with McGrath ${ }^{\mathrm{TM}}$ than with Macintosh laryngoscope in uncomplicated tracheal intubation [127]. Ray et al. [128] reported that novices achieved a higher successful tracheal intubation with less dental trauma with the McGrath ${ }^{\mathrm{TM}}$ compared with the Macintosh laryngoscope, while intubation time was similar. In the study using manikin to compare Glidescope $^{\mathrm{TM}}$, McGrath ${ }^{\mathrm{TM}}$, Airtraq $^{\mathrm{TM}}$, and Macintosh laryngoscopes, Airtraq ${ }^{\mathrm{TM}}$ consistently provided the most rapid intubation. Laryngeal grade views were superior with the Airtraq $^{\mathrm{TM}}$ and McGrath ${ }^{\mathrm{TM}}$ than with the Glidescope ${ }^{\mathrm{TM}}$ [129].

The LMA CTrach ${ }^{\mathrm{TM}}$ (SEBAC, Pantin, France) is an intubating laryngeal mask airway with a detachable liquid crystal display. This system enables viewing of the larynx and the process of endotracheal intubation through the laryngeal mask airway. However, the display is too big to attach it to the LMA during insertion. Therefore, the display should be attached after insertion of the device. The mean time to see the glottis and tracheal intubation were shorter with the Airtraq ${ }^{\mathrm{TM}}$ than the $\operatorname{LMA~CTrach}^{\mathrm{TM}}[130]$.

StyletScope $^{\mathrm{TM}}$ (Nihon Kohden, Tokyo, Japan) uses a plastic fiberoptic imaging system incorporated into an endotracheal tube stylet that can be flexed by the handle. Intubation time was significantly shorter with Airway Scope ${ }^{\mathrm{TM}}$ than with StyletScope $^{\mathrm{TM}}$ [131]. Many other this kind of devices have been developed, but not so much used.

In summary, Airway Scope ${ }^{\mathrm{TM}}$, Airtraq ${ }^{\mathrm{TM}}$, and McGrath ${ }^{\mathrm{TM}}$ might be better than other devices for difficult intubation, while for patients with Cormack and Lehane classification 1 or 2 , these devices are not necessary because Macintosh is better.

\section{Pulse Oximeter}

Pulse oximeter is now one of the routine monitors to know oxygen saturation. However, it is well known that skin pigmentation, dye infusion, peripheral hypothermia, etc. interfere the measurement of pulse oximeter. Van Oostrom et al. [132] reported that a flameless stereotactic neurosurgical positioning system reduced the accuracy of pulse oximeter measurement. Infrared pulse waves from neurosurgical navigation system also interfere with pulse oximeter measurement [133]. A single layer of aluminum may inhibit the interference.

Some new indices using pulse oximeter are developed. Plethysmographic (pulse oximetry) waveform variation and delta pulse oximetry plethysmography increased significantly by hypovolemia [134].

Photoplethysmographic waveform variation is used to detect volume changes in the microvascular bed of tissues [135] and it is also a reliable monitor of changes of sympathetic function [136]. Perfusion index derived from photoplethysmography waveform analysis provides an earlier and a clearer indication of sympathetic block than changes in blood pressure [137].

Pleth variability index is a new algorithm allowing for automated and continuous calculation of respiratory variations in the pulse oximeter plethysmographic waveform amplitude. In patients ventilated with tidal volume over $8 \mathrm{ml} / \mathrm{kg}$ under sedation, pleth variability index can detect hemodynamic effects of positive end-expiratory pressure [138].

In summary, similar to arterial waveform analysis, some indices derived from pulse oximeter waveform are developed. However, these might have more variations than arterial waveform analysis in author's experience, which make these difficult to be popular.

\section{Cerebral Monitoring}

Intracranial pressure is sometimes monitored postoperatively or in patients with traumatic brain injury. To measure intracranial pressure, we need to insert the catheter. As a noninvasive monitor, transcranial Doppler (TCD) has been used to measure cerebral blood flow of major intracranial artery such as middle cerebral artery, anterior cerebral artery, vertebral artery, etc. It is commonly used to detect vasospasm after subarachnoid hemorrhage. After the experience of brain stem infarction after aortic arch replacement for dissecting aortic arch aneurysm, the author routinely check blood flow of both vertebral artery by TCD before such surgery to determine whether we need to supply every three branches of aortic arch. Engelhardt et al. [139] showed that detection of foramen ovale using TCD and contrast medium before surgery scheduled in sitting position was useful to avoid air embolism. TCD is also used to check autoregulation of cerebral blood flow [140] and cerebral perfusion during carotid endarterectomy [141]. For continuous monitoring, the probe of TCD should be kept in the same position, but it needs high skill, which is the problem to use TCD during general anesthesia.

During carotid endarterectomy, Pugliese et al. [141] said that regional cerebral oxygen saturation $\left(\mathrm{SctO}_{2}\right)$ measured by nearinfrared spectroscopy (INVOS Cerebral Oximeter ${ }^{\mathrm{TM}}$, Somanetics Troy, Michigan, USA) decreased with more relation with neurological symptom than blood flow velocity by TCD. They 
concluded that $\mathrm{SctO}_{2}$ is better than cerebral blood flow velocity to detect cerebral hypoxia. However, when $\mathrm{SctO}_{2}$ decreases, neurological symptom occurs, which means it is too late when $\mathrm{SctO}_{2}$ decreases. Therefore, from their results, the author thinks that decrease in cerebral blood flow velocity should be used to avoid hypoxic brain damage. Fischer et al. [142] also reported that decrease in $\mathrm{SctO}_{2}$ correlated well with decrease in blood pressure and increase in $\mathrm{SctO}_{2}$ correlated well with increase in $\mathrm{EtCO}_{2}$ in beach chair position to conclude that $\mathrm{SctO}_{2}$ was useful. However, if these correlations were well, blood pressure and $\mathrm{EtCO}_{2}$ are enough to suspect the changes of $\mathrm{SctO}_{2}$.

$\mathrm{SctO}_{2}$ shows local oxygen saturation, while jugular venous oxygen saturation $\left(\mathrm{SjO}_{2}\right)$ provides global cerebral oxygen consumption. In addition, increase in path length of nearinfrared light in pathologic conditions such as brain swelling can affect the accuracy of $\mathrm{SctO}_{2}$. Therefore, $\mathrm{SctO}_{2}$ should be interpreted carefully, while $\mathrm{SjO}_{2}$ may indicate the balance of cerebral blood flow and cerebral metabolic rate of oxygen.

Measurement of brain tissue oxygen partial pressure $\left(\mathrm{PbO}_{2}\right)$ is increasingly used in the intensive care unit. For this measurement, insertion of the sensor into brain parenchyma is necessary. $\mathrm{PbO}_{2}$ less than 8-10 mmHg shows a high risk of ischemia [143], tissue $\mathrm{pH}$ less than 7.0 and brain tissue carbon dioxide partial pressure $\left(\mathrm{PbCO}_{2}\right)$ greater than $60 \mathrm{mmHg}$ increase the risk of vasospasm [144]. Changes in $\mathrm{PbO}_{2}$ correlated well with changes $\mathrm{inSjO}_{2}$, particularly when the sensor was inserted into noncontusional area of brain [145].

Recently, cerebral microdialysis is applied in critically ill patients. This allows on-line monitoring of changes in brain tissue chemistry, achieved by inserting a catheter lined with polyamide dialysis membrane into brain parenchyma, which is perfused with a physiological solution. However, this has disadvantages such as disruption of local tissues, small hemorrhages, astrogliosis and macrophage infiltration [146], while cerebral microdialysis has great potential for exploring the pathophysiology of acute brain injury, pharmacokinetics of drugs within the central nervous system and the response to therapeutic intervention.

In summary, cerebral monitoring is difficult but quite important in the management of critically ill, therefore, further improvement or new development are expected.

\section{Conclusion}

Recent advance in clinical monitoring is tremendous. However, each monitor has advantage and disadvantage of its own. We should not completely trust on these monitors, but every time we need to combine some kinds of parameters to confirm patients status including traditional blood pressure, heart arte, etc.

\section{References}

1. Hirota K. Special cases: ketamine, nitrous oxide and xenon. Best Pract Res Clin Anaesthesiol 2006; 20: 69-79.

2. Scott JC, Cooke JE, Stanski DR. Electroencephalographic quantification of opioid effect: comparative pharmacodynamics of fentanyl and sufentanyl. Anesthesiology 1991; 74: 34-42.

3. Miyake W, Oda Y, Ikeda Y, Tanaka K, Hagihira S, Iwaki H, et al. Effect of remifentanil on cardiovascular and bispectral index responses following the induction of anesthesia with midazolam and subsequent tracheal intubation. J Anesth 2010; 24: 161-7.

4. Messner M, Beese U, Romstock J, Dinkel M, Tschaikowsky K. The bispectral index declines during neuromuscular block in fully awake persons. Anesth Analg 2003; 97: 488-91.

5. Nishiyama T, Matsukawa T, Hanaoka K. Is the ARX index a more sensitive indicator of anesthetic depth than the bispectral index during sevoflurane/nitrous oxide anesthesia? Acta Anaesthesiol Scand 2004; 48: 1028-32.

6. Meybohm P, Gruenewald M, Hocker J, Renner J, Graesner JT, Ilies C, et al. Correlation and agreement between the bispectral index vs. state entropy during hypothermic cardio-pulmonary bypass. Acta Anaesthesiol Scand 2010; 54: 169-75.

7. Mathew JP, Weatherwax KJ, East CJ, White WD, Reves JG. Bispectral analysis during cardiopulmonary bypass: the effect of hypothermia on the hypnotic state. J Clin Anesth 2001; 13: 301-5.

8. Niedhart DJ, Kaiser HA, Jacobsohn E, Hantler CB, Evers AS, Avidan MS. Intrapatient reproducibility of the BISxp monitor. Anesthesiology 2006; 104: 242-8.

9. Viertio-Oja H, Maja V, Sarkela M, Alja P, Tenkanen N, TolvanenLaakso H, et al. Description of the Entropy ${ }^{\mathrm{TM}}$ algorithm as applied in the Datex-Ohmeda $\mathrm{S} / 5^{\mathrm{TM}}$ Entropy module. Acta Anaesthesiol Scand 2004; 48: 154-61.

10. Aho AJ, Yli-Hankala A, Lyytikainen LP, Jantti V. Facial muscle activity, response entropy, and state entropy indices during noxious stimuli in propofol-nitrous oxide or propofol-nitrous oxide-remifentanil anaesthesia without neuromuscular block. Br J Anaesth 2009; 102: 227-33.

11. Nishiyama T. Cerebral state index vs. bispectral index during sevoflurane-nitrous oxide anaesthesia. Eur J Anaesthesiol 2009; 26: 638-42.

12. Cortinez LI, Delfino AE, Fuentes R, Munoz HR. Performance of the cerebral state index during increasing levels of propofol anesthesia: a comparison with the bispectral index. Anesth Analg 2007; 104: 605-10.

13. Kreuer S, Biedler A, Larsen R, Schoth S, Altmann S, Wilhelm W. The Narcotrend - a new EEG monitor designed to measure the depth of anaesthesia. A comparison with bispectral index monitoring during propofol-remifentanil-anaesthesia. Anaesthesist 2001; 50: 921-5.

14. Chabot RJ, Gugino LD, Aglio LS, Maddi R, Cote W. QEEG and neuropsychological profiles of patients after cardiopulmonary bypass surgical procedures. Clin Electroencephalogr 1997; 28: 98-105.

15. Revuelta M, Paniagua P, Campos JM, Fernandez JA, Martinez A, Jospin $\mathrm{M}$, et al. Validation of the index of consciousness during sevoflurane and remifentanil anaesthesia: a comparison with the bispectral index and the cerebral state index. Br J Anaesth 2008; 
101: 653-8.

16. Thornton C, Sharpe RM. Evoked responses in anaesthesia. Br J Anaesth 1998; 81: 771-81.

17. de Beer NA, van Hoff JC, Brunia CH, Cluitmans PJ, Korsten $\mathrm{HH}$, Beneken JE. Midlatency auditory evoked potentials as indicators of perceptual processing during general anaesthesia. Br J Anaesth 1996; 77: 617-24.

18. Urhonen E, Jensen EW, Lund J. Changes in rapidly extracted auditory evoked potentials during tracheal intubation. Acta Anaesthesiol Scand 2000; 44: 743-8.

19. Nishiyama T. Comparison of the two different monitors of auditory evoked potentials index in propofol-fentanyl-nitrous oxide anesthesia. J Clin Anesth 2009; 21: 551-4.

20. Nishiyama T. Comparison of the bispectral index, spectral edge frequency and auditory evoked potentials index in isofluranenitrous oxide anesthesia. Anesth Res 2008; 44: 11-15.

21. Nishiyama T. Auditory evoked potentials index versus bispectral index during propofol sedation in spinal anesthesia. J Anesth 2009; 23: 26-30.

22. Nishiyama T, Hanaoka K. The A-line ARX index may be a more sensitive detector of arousal than the bispectral index during propofol-fentanyl-nitrous oxide anesthesia: a preliminary investigation. Can J Anesth 2004; 51: 539-44.

23. Nishiyama T, Matsukawa T, Hanaoka K. A compassion of the clinical usefulness of three different electroencephalogram monitors: Bispectral index, processed electroencephalogram, and Alaris auditory evoked potentials. Anesth Analg 2004; 98: 1341-5.

24. Nishiyama T. Changes in the auditory evoked potentials index by induction doses of four different intravenous anesthetics. Acta Anaesthesiol Scand 2005; 49: 1326-9.

25. Blussé van Oud-Alblas HJ, Peters JW, de Leeuw TG, Vermeylen KT, de Klerk LW, Tibboel D, et al. A comparison in adolescents of composite auditory evoked potential index and bispectral index during propofol-remifentanil anesthesia for scoliosis surgery with intraoperative wake-up test. Anesth Analg 2008; 107: 1683-8.

26. Nishiyama T. The effects of auditory evoked potential click sounds on bispectral index and entropy. Anesth Analg 2008; 107: 545-8.

27. Bowdle TA. Depth of anesthesia monitoring. Anesthesiol Clin 2006; 24: 793-822.

28. Storm H, Fremming A, Oedegaard S, Martinsen OG, Moerkrid L. The development of a software program for analyzing spontaneous and elicited skin conductance changes in infants and adults. Clin Neurophysiol 2000; 111: 1889-98.

29. Storm H. Skin conductance and the stress response from heel stick in preterm infants. Arch Dis Child Fetal Neonatal Ed 2000; 83: F143-7.

30. Critchley HD, Elliott R, Mathias CJ, Dolan RJ. Neural activity relating to generation and representation of galvanic skin conductance responses: a functional magnetic resonance imaging study. J Neurosci 2000; 20: 3033-40.

31. Edelberg A. Electrical properties of the skin. In : Methods in Psychophysiology. Edited by Brown CC: Baltimore, Williams \& Wilkins. 1967, pp 1-53.

32. Storm H, Shafiei M, Myre K, Raeder J. Palmar skin conductance compared to a developed stress score and to noxious and awakening stimuli on patients in anaesthesia. Acta Anaesthesiol Scand 2005; 49: 798-803.
33. Ledowski T, Bromilow J, Paech MJ, Storm H, Hacking R, Schug SA. Monitoring of skin conductance to assess postoperative pain intensity. Br J Anaesth 2006; 97: 862-5.

34. Ledowski T, Paech MJ, Storm H, Jones R, Schug SA. Skin conductance monitoring compared with bispectral index monitoring to assess emergence from general anaesthesia using sevoflurane and remifentanil. Br J Anaesth 2006; 97: 187-91.

35. Gjerstad AC, Storm H, Hagen R, Huiku M, Qvigstad E, Raeder J. Skin conductance or entropy for detection of non-noxious stimulation during different clinical levels of sedation. Acta Anaesthesiol Scand 2007; 51: 1-7.

36. Gjerstad AC, Storm H, Hagen R, Huiku M, Qvigstad E, Raeder J. Comparison of skin conductance with entropy during intubation, titanic stimulation and emergence from general anaesthesia. Acta Anaesthesiol Scand 2007; 51: 8-15.

37. Winterhaltera M, Munted S, Taschenbreckerc P, Heckerb H, Weilbachc C, Osthausc AW, et al. Skin impedance correlates to sedation grade, plasma propofol concentrations and bispectral index during a target-controlled infusion of propofol. Eur J Anaesthesiol 2009; 26: 589-96.

38. Ledowski T, Ang B, Schmarbeck T, Rhodes J. Monitoring of sympathetic tone to assess postoperative pain: skin conductance vs surgical stress index. Anaesthesia 2009; 64: 781-2.

39. Chen X, Thee C, Gruenwald M, Wnent J, Llies WJ, Hoeker C, et al. Comparison of surgical stress index-guided analgesia with standard clinical practice during routine general anesthesia a pilot study. Anesthesiology 2010; 112: 1175-83.

40. Luginbuhl M, Schumacher PM, Vuilleumier P, Vereecke H, Heyse B, Bouillon TW, et al. Noxious stimulation response index. A novel anesthetic state index based on hypnotic-opioid interaction. Anesthesiology 2010; 112: 872-80.

41. von Dincklage F, Hackbarth M, Mager R, Rehberg B, Baars JH. Monitoring of the responsiveness to noxious stimuli during anaethesia with propofol and remifentanil by using RIII reflex threshold and bispectral index. Br J Anaesth 2010; 104: 201-8.

42. Pomfrett CJ. Heart rate variability, BIS and 'depth of anaesthesia'. Br J Anaesth 1999; 82: 659-62.

43. Naito T. Energy index of heart rate spectral analysis for the assessment of autonomic nerve activities. Masui 1991; 40: 275-84.

44. Poyhonen M, Syvaoja S, Hartikainen J, Ruokonen E, Takala J. The effect of carbon dioxide, respiratory rate and tidal volume on human heart rate variability. Acta Anaesthesiol Scand 2004; 48 93-101.

45. Seitsonen ER, Korhonen IK, van Gils MJ, Huiku M, Lötjönen JM, Korttila KT, et al. EEG spectral entropy, heart rate, photoplethysmography and motor responses to skin incision during sevoflurane anaesthesia. Acta Anaesthesiol Scand 2005; 49: 28492.

46. Palazzolo JA, Estafanous FG, Murray PA. Entropy measures of heart rate variation in conscious dogs. Am J Physiol 1998; 274: H1099-105.

47. Billard V, Gambus PL, Chamoun N, Stanski DR, Shafer SL. A comparison of spectral edge, delta power, and bispectral index as EEG measures of alfentanil, propofol, and midazolam drug effect. Clin Pharmacol Ther 1997; 61: 45-58.

48. Nishiyama T. Entropy of heart rate variability and trend in electroencephalogram in propofol-fentanyl-nitrous oxide 
anesthesia. Anesth Res 2008; 44: 59-63.

49. Task Force of the European Society of Cardiology and the North American Society of Pacing and Electrophysiology. Heart rate variability. Standards of measurement, physiological interpretation, and clinical use. Circulation 1996; 93: 1043-65.

50. Ledowski T, Bein B, Hanss R, Paris A, Fudickar W, Scholz J, et al. Neuroendocrine stress response and heart rate variability: a comparison of total intravenous versus balanced anesthesia. Anesth Analg 2005; 101: 1700-5.

51. Pagani M, Montano N, Porta A, Malliani A, Abboud FM, Birkett C, et al. Relationship between spectral components of cardiovascular variabilities and direct measures of muscle sympathetic nerve activity in humans. Circulation 1997; 95: 1441-8.

52. Zhang L, Iwasaki K, Zuckerman JH, Behbehani K, Crandall CG, Levine BD. Mechanisim of blood pressure and R-R variability: insights from ganglion blockade in humans. J Physiol 2002; 543: 337-48.

53. Scheffer GJ, Ten-Voorde BJ, Karemaker JM, Ros HH, de Lange JJ. Effects of thiopentone, etomidate and propofol on beat-to-beat cardiovascular signals in man. Anaesthesia 1993; 48: 849-55.

54. Zickmann B, Hofmann HC, Pottkamper C, Knothe C, Boldt J, Hempelmann G. Changes in heart rate variability during induction of anesthesia with fentanyl and midazolam. J Cardiothorac Vasc Anesth 1996; 10: 609-13.

55. Nishiyama T. Heart rate variability during different anesthetic induction methods. Anesth Res 2009; 45: 31-4.

56. Win NN, Fukayama H, Kohase H, Umino M. The different effects of intravenous propofol and midazolam sedation on hemodynamic and heart rate variability. Anesth Analg 2005; 101: 97-102.

57. Kanaya N, Hirata N, Kurosawa S, Nakayama M, Namiki A. Differential effects of propofol and sevoflurane on heart rate variability. Anesthesiology 2003; 98: 34-40.

58. Komatsu T, Singh PK, Kimura T, Nishiwaki K, Bando K, Shimada $\mathrm{Y}$. Differential effects of ketamine and midazolam on heart rate variability. Can J Anaesth 1995; 42: 1003-9.

59. Ogawa Y, Iwasaki K, Shibata S, Kato J, Ogawa S, Oi Y. Different effects on circulatory control during volatile induction and maintenance of anesthesia and total intravenous anesthesia: autonomic nervous activity and arterial cardiac baroreflex function evaluated by blood pressure and heart rate variability analysis. J Clin Anesth 2006; 18: 87-95.

60. Maenpaa M, Penttila J, Laitio K, Kuusela T, Hinkka S, Scheinin $\mathrm{H}$. The effects of surgical levels of sevoflurane and propofol anaesthesia on heart rate variability. Eur J Anaesthesiol 2007; 24: 626-33.

61. Fujiwara Y, Kurokawa S, Shibata Y, Asakura Y, Harado M, Komatsu T. Sympathovagal effects of spinal anaesthesia with intrathecal or intravenous fentanyl assessed by heart rate variability. Acta Anaesthesiol Scand 2009; 53: 476-82.

62. Opdam HI, Wan L, Bellomo R. A pilot assessment of the FloTrac ${ }^{\mathrm{TM}}$ cardiac output monitoring system. Intensive Care Med 2007; 33: 344-9.

63. Lorsomradee S, Lprsomradee SR, Cromheecke S, De Hert SG. Continuous cardiac output measurement: arterial pressure analysis versus thermodilution technique during cardiac surgery with cardiopulmonary bypass. Anaesthesia 2007; 62: 979-83.
64. Staier K, Wiesenack C, Gunkel L, Keyl C. Cardiac output determination by thermodilution and arterial pulse waveform analysis in patients undergoing aortic valve replacement. Can J Anesth 2008; 55: 22-8.

65. Biasis M, Nouette-Gaulain K, Cottenceau V, Revel P, Sztark F. Uncalibrated pulse contour-derived stroke volume variation predicts fluid responsiveness in mechanically ventilated patients undergoing liver transplantation. Br J Anaesth 2008; 101: 761-8.

66. Matthieu B, Karine NG, Vincent C, Alain V, Francois CJ, Philippe $\mathrm{R}$, et al. Cardiac output measurement in patients undergoing liver transplantation: pulmonary artery catheter versus uncalibrated arterial pressure waveform analysis. Anesth Analg 2008; 106: 1480-6.

67. Cannesson M, Musard H, Desebbe O, Boucau C, Simon R, Henaine R, et al. The ability of stroke volume variations obtained with Vigileo/FloTrac system to monitor fluid responsiveness in mechanically ventilated patients. Anesth Analg 2009; 108: 513-7.

68. Lahner D, Kabon B, Marschalek C, Chiari A, Pestel G, Kaider A, et al. Evaluation of stroke volume variation obtained by arterial pulse contour analysis to predict fluid responsiveness intraoperatively. Br J Anaesth 2009; 103: 346-51.

69. Biais M, Bernard O, Ha JC, Degryse C, Sztark F. Abilities of pulse pressure variations and stroke volume variations to predict fluid responsiveness in prone position during scoliosis surgery. Br J Anaesth 2010; 104: 407-13.

70. Missant C, Rex S, Wouters PF. Accuracy of cardiac output measurements with pulse contour analysis $\left(\mathrm{PulseCO}^{\mathrm{TM}}\right)$ and Doppler echocardiography during off-pump coronary artery bypass grafting. Eur J Anaesthesiol 2008; 25: 243-8.

71. Yamashita K, Nishiyama T, Yokoyama T, Abe H, Manabe M. Cardiac output by Pulse $\mathrm{CO}^{\mathrm{TM}}$ is not interchangeable with thermodilution in patients undergoing OPCAB. Can J Anesth 2005; 52: 530-4.

72. Costa MG, Rocca GD, Chiarandini P, Mattelig S, Pompei L, Barriga MS, et al. Continuous and intermittent cardiac output measurement in hyperdynamic conditions: pulmonary artery catheter vs. lithium dilution technique. Intensive Care Med 2008; 34: 257-63.

73. Yamashita K, Nishiyama T, Yokoyama T, Abe H, Manabe M. Effects of vasodilation on cardiac output measured by PulseCO $^{\mathrm{TM}}$. J Clin Monit Comput 2007; 21: 335-9.

74. Belloni L, Pisano A, Natale A, Piccirillo MR, Piazza L, Ismeno G, et al. Assessment of fluid-responsiveness parameters for off-pump coronary artery bypass surgery: a comparison among LiDCO, transesophageal echocardiography, and pulmonary artery catheter. J Cardiothorac Vasc Anesth 2008; 22: 243-8.

75. L'e Orme RM, Pigott DW, Mihm FG. Measurement of cardiac output by transpulmonary arterial thermodilution using a long radial artery catheter. A comparison with intermittent pulmonary artery thermodilution. Anaesthesia 2004; 59: 590-4.

76. Harris AP, Miller CF, Beattie C, Rosenfeld GI, Rogers MC. The slowing of sinus rhythm during thermodilution cardiac output determination and the effect of altering injectate temperature. Anesthesiology 1985; 63: 540-1.

77. Lewis FR, Elings VB, Hill SL, Christensen JM. The measurement of extravascular lung water by thermal-green dye indicator dilution. Ann NY Acad Sci 1982; 384: 394-410. 
78. Schuerholz T, Meyer MC, Friedrich L, Przemeck M, Sumpelmann R, Marx G. Reliability of continuous cardiac output determination by pulse-contour analysis in porcine septic shock. Acta Anaesthesiol Scand 2006; 50: 407-13.

79. Yamashita K, Nishiyama T, Yokoyama T, Abe H, Manabe M. The effects of vasodilation on cardiac output measured by PiCCO. J Cardiothorac Vasc Anesth 2008; 22: 688-92.

80. Lichtwarck-Aschoff M, Zeravic J, Pfeiffer UJ. Intrathoracic blood volume accurately reflects circulatory volume status in critically ill patients with mechanical ventilation. Intensive Care Med 1992; 18: 142-7.

81. Mrtin GS, Eaton S, Mealer M, Moss M. Extravascular lung water in patients with severe sepsis: a prospective cohort study. Crit Care 2005; 9: R74-82.

82. Reuter DA, Bayerlein J, Goepfert MS, Weis FC, Kilger E, Lamm P, et al. Influence of tidal volume on left ventricular stroke volume variation measured by pulse contour analysis in mechanically ventilated patients. Intensive Care Med 2003; 29: 476-80.

83. Compton F, Wittrock M, Schaefer JH, Zidek W, Tepel M, Scholze A. Noninvasive cardiac output determination using applanation tonometry-derived radial artery pulse contour analysis in critically ill patients. Anesth Analg 2008; 106: 171-4.

84. Langewouters GJ, Wesseling KH, Goedhard WJ. The pressure dependent dynamic elasticity of 35 thoracic and 16 abdominal human aortas in vitro described by a five component model. J Biomech 1985; 18: 613-20.

85. de Wilde RB, Schreuder JJ, van den Berg PC, Jansen JR. An evaluation of cardiac output by five arterial pulse contour techniques during cardiac surgery. Anaesthesia 2007; 62: 760-8.

86. Kotake Y, Moriyama K, Innnami Y, Shimizu H, Ueda T, Morisaki H, et al. Performance of noninvasive partial $\mathrm{CO}_{2}$ rebreathing cardiac output and continuous thermodilution cardiac output in patients undergoing aortic reconstruction surgery. Anesthesiology 2003; 99: 283-8.

87. Yamashita K, Yokoyama T, Abe H, Kitaoka N, Nishiyama T, Manabe M. Is the thoracic electrical bioimpedance method by the BioZ.com ${ }^{\mathrm{TM}}$ useful to measure cardiac output in cardiac surgery? Circ Cont 2003; 24: 371-3

88. Raue W, Swierzy M, Koplin G, Schwenk W. Comparison of electrical velocimetry and transthoracic thermodilution technique for cardiac output assessment in critically ill patients. Eur J Anaesthesiol 2009; 26: 1067-71.

89. Gunn SR, Kim HK, Harrigan PW, Pinsky MR. Ability of pulse contour and esophageal Doppler to estimate rapid changes in stroke volume. Intensive Care Med 2006; 32: 1537-46.

90. American Society of Anesthesiologists. Practice guidelines for perioperative transesophageal echocardiography. Anesthesiology 2010; 112: 1084-96.

91. Bodenham AR. Can you justify not using ultrasound guidance for central venous access? Crit Care 2006; 10: 175.

92. Levin PD, Sheinin O, Gozal Y. Use of ultrasound guidance in the insertion of radial artery catheters. Crit Care Med 2003; 31: 481-4.

93. Sharma A, Bodenham AR, Mallick A. Ultrasound-guided infraclavicular axillary vein cannulation for central venous access. Br J Anaesth 2004; 93: 188-92.

94. Soeding PE, Sha S, Royse CE, Marks P, Hoy G, Royse AG. A randomized trial of ultrasound-guided brachial plexus anesthesia in upper limb surgery. Anaesth Intensive Care 2005; 33: 719-25.

95. Klein SM, Fronheiser MP, Reach J, Nielsen KC, Smith SW. Piezoelectric vibrating needle and catheter for enhancing ultrasound-guided peripheral nerve block. Anesth Analg 2007; 105: 1858-60.

96. Swenson JD, Brown NA. Evaluation of a new fenestrated needle for ultrasound-guided fascia iliaca block. J Clin Anesth 2007; 19: 175-9.

97. Orebaugh SL, Williams BA, Kentor ML. Ultrasound guidance with nerve stimulation reduces the time necessary for resident peripheral nerve blockade. Reg Anesth Pain Med 2007; 32: 448-54.

98. Schwemmer U, Markus CK, Greim CA, Brederlau J, Roewer N. Ultrasound-guided anaesthesia of the axillary brachial plexus: efficacy of multiple injection approach. Ultraschall Med 2005; 26: 114-9.

99. Riazi S, Carmichael N, Awad I, Holtby RM, McCartney CJ. Effect of local anaesthetic volume ( $20 \mathrm{vs} 5 \mathrm{ml}$ ) on the efficacy and respiratory consequences of ultrasound-guided interscalene brachial plexus block. Br J Anaesth 2008; 101: 549-56.

100. Casati A, Danelli G, Baciarello M, Corradi M, Leone S, Di Cianni S, et al. A prospective, randomized comparison between ultrasound and nerve stimulation guidance for multiple injection axillary brachial plexus block. Anesthesiology 2007; 106: 992-6.

101. Fredrickson MJ, Ball CM, Dalgleish AJ. A prospective randomized comparison of ultrasound guidance versus neurostimulation for interscalene catheter placement. Reg Anesth Pain Med 2009; 34: 590-4.

102. Grau T, Leipold RW, Conradi R, Martin E, Motsch J. Ultrasound imaging of the thoracic epidural space. Reg Anaesth Pain Med $2002 ; 27: 200-6$.

103. Marhofer P, Greher M, Sitzwohl C, Kapral S. Ultrasonographic guidance for infraclavicular plexus anaesthesia in children. Anaesthesia 2004; 59: 642-6.

104. French JL, Raine-Fenning NJ, Hardman JG, Bedforth NM. Pitfalls of ultrasound guided vascular access: the use of three-fourdimensional ultrasound. Anaesthesia 2008; 63: 806-13.

105. Cash CJ, Sardesai AM, Berman LH, Herrick MJ, Treece GM, Prager RW, et al. Spatial mapping of the brachial plexus using threedimensional ultrasound. Br J Radiol 2005; 78: 1086-94.

106. Wahba RW, Tessler MJ. Misleading end-tidal $\mathrm{CO}_{2}$ tensions. Can J Anaesth 1996; 43: 862-6.

107. Martin RJ, Herrell N, Pultusker M. Transcutaneous measurement of carbon dioxide tension: effect of sleep state in term infants. Pediatrics 1981; 67: 622-5.

108. Palmisano BW, Severinghaus JW. Transcutaneous $\mathrm{PCO}_{2}$ and $\mathrm{PO}_{2}$ : a multicenter study of accuracy. J Clin Monit 1990; 6: 189-95.

109. Nishiyama T, Nakamura S, Yamashita K. Comparison of the transcutaneous oxygen and carbon dioxide tension in different electrode locations during general anaesthesia. Eur J Anaesthesiol 2006; 23: 1049-54.

110. Baulig W, Schutt P, Roth HR, Hayoz J, Schmid ER. Clinical validation of a digital transcutaneous $\mathrm{PCO}_{2} / \mathrm{SpO}_{2}$ sensor in adult patients after cardiac surgery. J Clin Monit Comput 2007; 21: 3039.

111. Nishiyama T, Nakamura S, Yamashita K. Effects of the electrode temperature of a new monitor, TCM4, on the measurement of transcutaneous oxygen and carbon dioxide tension. J Anesth 
2006; 20: 331-4.

112. Kagawa S, Otani N, Kamide M, Gisiger PA, Eberhard P, Severinghaus JW. Initial transcutaneous $\mathrm{PCO}_{2}$ overshoot with ear probe at 42 degrees C. J Clin Monit Comput 2004; 18: 343-5.

113. Reid CW, Martineau RJ, Miller DR, Hull KA, Baines J, Sullivan PJ. A comparison of transcutaneous, end-tidal and arterial measurements of carbon dioxide during general anesthesia. Can J Anaesth 1992; 39: 31-6.

114. Hirabayashi M, Fujiwara C, Ohtani N, Kagawa S, Kamide M. Transcutaneous $\mathrm{PCO}_{2}$ monitors are more accurate than end-tidal $\mathrm{PCO}_{2}$ monitors. J Anesth 2009; 23: 198-202.

115. De Oliveira GS Jr, Ahmad S, Fitzgerald PC, McCarthy RJ. Detection oh hypoventilation during sedation in patients undergoing ambulatory gynaecological hysteroscopy: a comparison between transcutaneous and nasal end-tidal carbon dioxide measurements. Br J Anaesth 2010; 104: 774-8.

116. Kopka A, Wallace E, Reilly G, Binning A. Observational study of perioperative $\mathrm{PtCCO}_{2}$ and $\mathrm{SpO}_{2}$ in non-ventilated patients receiving epidural infusion of patient-controlled analgesia using a single earlobe monitor (TOSCA). Br J Anaesth 2007; 99: 567-71.

117. McCormack JG, Kelly KP, Wedgwood J, Lyon R. The effects of different analgesic regimens on transcutaneous $\mathrm{CO}_{2}$ after major surgery. Anaesthesia 2008; 63: 814-21.

118. Bolliger D, Steiner LA, Kasper J, Aziz OA, Filipovic M, Seeberger MD. The accuracy of non-invasive carbon dioxide monitoring: a clinical evaluation of two transcutaneous systems. Anaesthesia 2007; 62: 394-9.

119. Nishiyama T. Changes in percutaneous oxygen tension induced by spinal anesthesia. J Anesth 2007; 21: 317-9.

120. Higgins MS, Deshphande JK, Badr A. New video system improves teaching of direct laryngoscopy. Anesthesiology 1996; 84: 1010-1.

121. Low D, Healy D, Rasburn N. The use of the BERCI DCI ${ }^{\mathrm{TM}}$ Video Laryngoscope for teaching novices direct laryngoscopy and tracheal intubation. Anaesthesia 2008; 63: 195-201.

122. Stroumpoulis K, Pagoulatou A, Violari M, Ikonomou I, Kalantzi $\mathrm{N}$, Kastrinaki K, et al. Videolaryngoscopy in the management of the difficult airway: a comparison with the Macintosh blade. Eur J Anaesthesiol 2009; 26: 218-22.

123. Liu L, Tanigawa K, Kusunoki S, Tamura T, Ota K, Yamaga S, et al. Tracheal intubation of a difficult airway using Airway Scope, Airtraq, and Macintosh laryngoscope: a comparative manikin study of inexperienced personnel. Anesth Analg 2010; 110: 104955.

124. Malik MA, Subramaniam R, Maharaj CH, Harte BH, Laffey JG. Randomized controlled trial of the Pentax AWS, Glidescope, and Macintosh laryngoscopes in predicted difficult intubation. $\mathrm{Br} \mathrm{J}$ Anaesth 2009; 103: 761-8.

125. Tan BH, Liu EHC, Lim RT, Liow LM, Goy RW. Ease of intubation with the GlideScope or Airway Scope by novice operators in simulated easy and difficult airways - a manikin study. Anaesthesia 2009; 64: 187-90.

126. Malik MA, O'Donoghue C, Carney J, Maharaj CH, Harte BH, Laffey JG. Comparison of the Glidescope, the Pentax AWS, and the Truview $\mathrm{EVO}_{2}$ with the Macintosh laryngoscope in experienced anaesthetists: a manikin study. Br J Anaesth 2009; 102: 128-134.

127. Walker L, Brampton W, Halai M, Hoy C, Lee E, Scott I, et al. Randomized controlled trial of intubation with the McGrath
Series 5 videolaryngoscope by inexperienced anaesthetists. Br J Anaesth 2009; 103: 440-5.

128. Ray DC, Billington C, Kearns PK, Kirkbride R, Mackintosh $\mathrm{K}$, Reeve CS, et al. A comparison of McGrath and Macintosh laryngoscopes in novice users: a manikin study. Anaesthesia 2009; 64: 1207-10.

129. Savoldelli GL, Schiffer E, Abegg C, Baeriswyl V, Clergue F, Waeber JL. Comparison of the Glidescope, the McGrath, the Airtraq and the Macintosh laryngoscopes in simulated difficult airways. Anaesthesia 2008; 63: 1358-64.

130. Arslan ZI, Yildiz T, Baykara ZN, Solak M, Toker K. Tracheal intubation in patients with rigid collar immobilization of the cervical spine: a comparison of Airtraq and LMA Ctrach devices. Anaesthesia 2009; 64: 1332-6.

131. Komatsu R, Kamata K, Hamada K, Sessler DI, Ozaki M. Airway Scope and StyletScope for tracheal intubation in a simulated difficult airway. Anesth Analg 2009; 108: 273-9.

132. van Oostrom JH, Mahla ME, Gravestein D. The Stealth Station Image Guidance System may interfere with pulse oximetry. Can J Anaesth 2005; 52: 379-82.

133. Mathes AM, Kreuer S, Schneider SO, Ziegeler S, Grundmann U. The performance of six pulse oximeters in the environment of neuronavigation. Anesth Analg 2008; 107: 541-4.

134. Pizov R, Eden A, Bystritski D, Kalina E, Tamir A, Gelman S. Arterial and plethysmographic waveform analysis in anesthetized patients with hypovolemia. Anesthesiology 2010; 113: 83-91.

135. Reisner A, Shaltis PA, McCombie D, Asada HH. Utility of the photoplethysmogram in circulatory monitoring. Anesthesiology 2008; 108: 950-8.

136. Nitzen M, Babchenko A, Shemesh D, Alberton J. Influence of thoracic sympathectomy on cardiac induced oscillations in tissue blood volume. Med Biol Eng Comput 2001; 39: 579-83.

137. Ginosar Y, Weiniger CF, Meroz Y, Kurz V, Bdolah-Abram T, Babchenko A, et al. Pulse oximeter perfusion index as an early indicator of sympathectomy after epidural anesthesia. Acta Anaesthesiol Scand 2009; 53: 1018-26.

138. Desebbe O, Boucau C, Farhat F, Bastien O, Lehot JJ, Cannesson M. The ability of pleth variability index to predict the hemodynamic effects of positive end-expiratory pressure in mechanically ventilated patients under general anesthesia. Anesth Analg 2010; 110: 792-8.

139. Engelhardt M, Folkers W, Brenke C, Scholz M, Harders A, Fidorra $\mathrm{H}$, et al. Neurosurgical operations with the patient in sitting position: analysis of risk factors using transcranial Doppler sonography. Br J Anaesth 2006; 96: 467-72.

140. Nishiyama T, Matsukawa T, Yokoyama T, Hanaoka K. Cerebrovascular carbon dioxide reactivity during general anesthesia: a comparison between sevoflurane and isoflurane. Anesth Analg 1999; 89: 1437-41.

141. Pugliese F, Ruberto F, Tosi A, Martelli S, Bruno K, Summonti D, et al. Regional cerebral saturation versus transcranial Doppler during carotid endarterectomy under regional anaesthesia. Eur J Anaesthesiol 2009; 26: 643-7.

142. Fischer GW, Torrillo TM, Weiner MM, Rosenblatt MA. The use of cerebral oximetry as a monitor of the adequacy of cerebral perfusion in a patient undergoing shoulder surgery in the beach chair position. Pain Practice 2009; 9: 304-7. 
143. Ketty-White R, Hutchinson PJ, Al-Rawi PG, Gupta AK, Pickard JD, Kirkpatrick PJ. Adverse cerebral events detected after subarachnoid hemorrhage using brain oxygen and microdialysis probes. Neurosurgery 2002; 50: 1213-21.

144. Charbel FT, Du X, Hoffmann WE, Ausman JI. Brain tissue $\mathrm{PO}_{2}$, $\mathrm{PCO}_{2}$, and $\mathrm{pH}$ during cerebral vasospasm. Surg Neurol 2000; 54: 432-7.

145. Gupta AK, Hutchinson PJ, AI-Rawi P, Gupta S, Swart M, Kirkpatrick
PJ, et al. Measurement of brain tissue oxygenation compared with jugular venous oxygen saturation for monitoring cerebral oxygenation after traumatic brain injury. Anesth Analg 1999; 88: 549-53.

146. Whittle IR, Glasby M, Lammie A, Bell H, Ungerstedt U. Neuropathological findings after intracerebral implantation of microdialysis catheters. Neuroreport 1998; 9: 2821-5. 